\title{
Shared decision making: really putting patients at the centre of healthcare
}

Despite being correct at proof stage, the name of the first author of reference 14 in this Analysis article by A M Stiggelbout and colleagues (BMJ 2012;344:e256, doi:10.1136/bmj.e256) was wrongly spelt as Iwyn $\mathrm{G}$ in the final publication. Reference 14 should have read: "Elwyn G, Edwards A, Kinnersley P, Grol R. Shared decision making and the concept of equipoise: the competences of involving patients in healthcare choices. $\mathrm{Br} J$ Gen Pract 2000;50:892-9."

Cite this as: BMJ 2012;344:e863

๑ BMJ Publishing Group Ltd 2012 